Article

\title{
Role of Ionic Headgroups on the Thermal, Rheological, and Foaming Properties of Novel Betaine-Based Polyoxyethylene Zwitterionic Surfactants for Enhanced Oil Recovery
}

\author{
Muhammad Shahzad Kamal ${ }^{D}$, Syed Muhammad Shakil Hussain * and Lionel Talley Fogang \\ Center for Integrative Petroleum Research, King Fahd University of Petroleum \& Minerals, Dhahran 31261, \\ Saudi Arabia; shahzadmalik@kfupm.edu.sa (M.S.K.); lionelfogang@kfupm.edu.sa (L.T.F.) \\ * Correspondence: smshakil@kfupm.edu.sa; Tel.: +966-13-860-2156; Fax: +966-13-860-3989
}

Received: 3 November 2019; Accepted: 25 November 2019; Published: 3 December 2019

\begin{abstract}
Long-term thermal stability of surfactants under harsh reservoir conditions is one of the main challenges for surfactant injection. Most of the commercially available surfactants thermally degrade or precipitate when exposed to high-temperature and high-salinity conditions. In this work, we designed and synthesized three novel betaine-based polyoxyethylene zwitterionic surfactants containing different head groups (carboxybetaine, sulfobetaine, and hydroxysulfobetaine) and bearing an unsaturated tail. The impact of the surfactant head group on the long-term thermal stability, foam stability, and surfactant-polymer interactions were examined. The thermal stability of the surfactants was assessed by monitoring the structural changes when exposed at high temperature $\left(90{ }^{\circ} \mathrm{C}\right.$ ) for three months using ${ }^{1} \mathrm{H}-\mathrm{NMR},{ }^{13} \mathrm{C}-\mathrm{NMR}$, and FTIR analysis. All surfactants were found thermally stable regardless of the headgroup and no structural changes were evidenced. The surfactant-polymer interactions were dominant in deionized water. However, in seawater, the surfactant addition had no effect on the rheological properties. Similarly, changing the headgroup of polyoxyethylene zwitterionic surfactants had no major effect on the foamability and foam stability. The findings of the present study reveal that the betaine-based polyoxyethylene zwitterionic surfactant can be a good choice for enhanced oil recovery application and the nature of the headgroup has no major impact on the thermal, rheological, and foaming properties of the surfactant in typical harsh reservoir conditions (high salinity, high temperature).
\end{abstract}

Keywords: polyoxyethylene; rheology; foam; polymer; thermal stability

\section{Introduction}

Surfactants consist of head groups (hydrophilic) and tail groups (hydrophobic) and are mainly used to change the surface properties at the gas-liquid (surface tension), liquid-liquid (interfacial tension), and solid-liquid (wettability) interface. Surfactants are classified as nonionic, cationic, anionic, and zwitterionic based on the nature of the headgroup. Zwitterionic surfactants contain both cationic and anionic active groups and have serval advantages over other classes of surfactants, such as better foam stability, low toxicity, salt tolerance, biodegradability, temperature stability, and improved water solubility [1,2]. These types of surfactants have been used in coating, painting, textiles, pharmaceutical, and oilfield applications [3-6].

In oilfield applications, surfactants have been used in well stimulation, acid diversion, drilling fluids, and enhanced oil recovery (EOR) [7-13]. Enhanced oil recovery techniques are applied at tertiary stages in a reservoir and $30 \%$ to $60 \%$ extra crude oil can be recovered using different EOR techniques [14]. EOR techniques mainly include gas injection, and thermal and chemical EOR [15]. In recent years, 
carbonated water $\left(\mathrm{CO}_{2}\right.$-enriched) injection has also been proven as an alternative to conventional gas flooding that needs only a small amount of $\mathrm{CO}_{2}$ [16]. In chemical EOR, different chemicals, such as polymers, surfactants, nanoparticles, and alkaline, are introduced to enhance oil recovery. Polymers tend to enhance the viscosity of the introduced water and increase the mobility ratio [17-19]. Alkalis are injected to reduce the surfactant adsorption and form surfactant inside the reservoir. Nanoparticles and nanofluid injection are key in the chemical EOR process. Such nanoparticles and nanofluids can be used individually or in combination with other chemicals, including surfactants [20]. Surfactants tend to lower interfacial tension (IFT) in oil and aqueous, stabilize oil/water emulsions, alter the wettability of rocks, and are used as a foaming agent in different gas flooding processes [21-26]. However, most of the commercially available surfactants thermally degrade in high-salinity and high-temperature environments. Thermal stability in reservoir conditions is a pre-requisite for surfactants' application in EOR and other oilfield applications. Betaine-type surfactants have shown excellent thermal stability in high-salinity and high-temperature environments $[27,28]$. We were further interested in evaluating the impact of different ionic headgroups on the thermal stability of betaine-type polyoxyethylene zwitterionic surfactants, which has not been reported in the literature.

Surfactant-polymer interactions are also important as surfactants are injected with polymers to improve mobility and to achieve ultra-low interfacial tension, simultaneously. Rheological properties of surfactant-polymer solution can identify the type of interactions between the surfactant and polymer. For EOR applications, it is extremely important to know how the injected surfactant interacts with the polymer. Partially hydrolyzed polyacrylamide (HPAM) is usually the extensively applied polymer for chemical EOR applications because of the large hydrodynamic volume, low cost, and its availability on the commercial scale. HPAM is a preferred choice for low salinity and low temperature conditions and it is avoided in high salinity and high temperature conditions owing to its poor stability in harsh environments [29]. Replacing some of the acrylate monomers with other monomers, including 2-acrylamido-2-methylpropane sulfonic acid (AMPS), can significantly improve the thermal stability. Therefore, a copolymer of acrylamide (AM) and AMPS was selected to evaluate the interactions between surfactant and polymers. The AM-AMPS copolymer has shown improvements in thermal and electrolyte stability compared to HPAM [30].

The foaming properties of surfactants are also important for oilfield applications, such as in gas injection-based EOR processes. Foam is mainly used to improve the macroscopic sweep by decreasing the mobility of the injected gas and by diverting the gas to low permeability zones of the reservoir [31]. The channeling, which is a typical issue in heterogeneous reservoirs, can be minimized by foam as it is more stable in high permeability zones. This stability in high permeability zones increases the flow resistance and diverts the gas to low permeability zones. Because of the reduced mobility of the displacing fluid, the effect of gravity is overridden and viscous fingering is also lessened. Foam mainly consists of gas bubbles that are separated by liquid films and enhance the properties of liquids [32]. To ensure the maximum performance of a surfactant for foam flooding, it should generate a stable foam under the given conditions.

In this work, the impact of different headgroups on the thermal stability, surfactant-polymer interactions, and foaming properties of three newly synthesized betaine-based polyoxyethylene surfactants, namely oleyl polyoxyethylene amidopropyl hydroxy sulfobetaine (OPAH), oleyl polyoxyethylene amidopropyl sulfobetaine (OPAS), and oleyl polyoxyethylene amidopropyl carboxybetaine (OPAC), were investigated. The synthesis and surface properties of these surfactants were already reported in our previous publication [33].

\section{Experimental}

\subsection{Materials}

The material used for the preparation of OPAH, OPAS, and OPAC was depicted in our preceding article [33]. The salinity of the synthetic seawater (SW) was $57,643 \mathrm{ppm}$ and was prepared by the use 
of laboratory-grade chemicals, such as $\mathrm{NaCl}, \mathrm{Na}_{2} \mathrm{SO}_{4}, \mathrm{MgCl}_{2}, \mathrm{CaCl}_{2}$, and $\mathrm{NaHCO}_{3}$. All chemicals for synthetic seawater preparation were obtained from Sigma Aldrich (St. Louis, MO, USA). The detailed composition of synthetic seawater is given in our previous article [34]. The copolymer of acrylamide and 2-acrylamido-2-methylpropane sulfonic acid (AM-AMPS) was obtained from SNF Floerger, Andrézieux, France. The polymer has a molar mass of 8 million Dalton along with $25 \%$ degree of anionicity. The structures of surfactants and polymers are given in Figure 1.<smiles>CN(CCCNC(=O)COCCOC(C)(C)CC=CCC(C)(C)C)CC(=O)O</smiles><smiles>CN(CCCNC(=O)COCCOCCCCCC(C)(C)C)CCCS(=O)(=O)[O-]</smiles><smiles>CN(CCCNC(=O)COCCOCCC=CCC(C)(C)C)CC(O)CS(=O)(=O)[O-]</smiles>

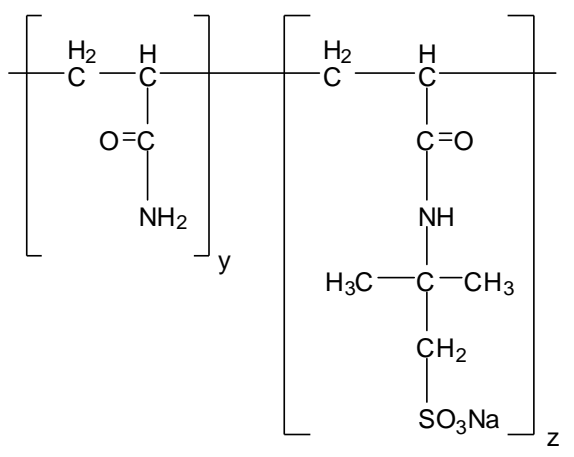

AM-AMPS co-polymer

Figure 1. The structures of the surfactants and polymer used in this study.

\subsection{Long-Term Thermal Stability}

NMR analysis of before and after the thermal treatment of surfactants samples with SW and deionized water (DW) was performed on a JEOL 1500 instrument (500 MHz) (JEOL, Tokyo, Japan) using TMS (internal standard) and chloroform-d as a solvent. The data were received in ppm. FTIR analysis of thermally treated surfactant samples was done on a Perkin-Elmer instrument (16F model, Perkin-Elmer, Waltham, MA, USA). The data were acquired in $\mathrm{cm}^{-1}$.

\subsection{Rheology}

Rheology of the surfactant-polymer mixtures was measured with a rheometer (Discovery Hybrid Rheometer 3, TA Instruments, New Castle, DE, USA) in a DIN concentric cylinder geometry (cup diameter $=30.38 \mathrm{~mm}$, bob diameter $=27.97 \mathrm{~mm}$, bob length $=41.90 \mathrm{~mm}$ ). The following rheological tests were conducted: Steady shear rheology, dynamic shear rheology, and oscillation temperature ramp. Both steady and dynamic shear rheology were performed at $80^{\circ} \mathrm{C}$, whereas the oscillation temperature ramp was conducted from 20 to $90^{\circ} \mathrm{C}$. The heating rate of the temperature ramp test was $2{ }^{\circ} \mathrm{C} / \mathrm{min}$. Dynamic rheology and oscillation temperature ramp were conducted within the linear viscoelastic region of the samples. A shear rate range of 0.001 to $10001 / \mathrm{s}$ was used for steady shear rheology, while the angular frequency range for dynamic rheology was 0.1 to $100 \mathrm{rad} / \mathrm{s}$. The samples were soaked at $80^{\circ} \mathrm{C}$ for 2 min before these tests. The samples were covered with a solvent trap to reduce the effect of evaporation on the experiments.

\subsection{Foam Analysis}

Foam characteristics of the surfactant solutions were measured with a dynamic foam analyzer (DFA 100, Krüss GmbH, Hamburg, Germany) at $22{ }^{\circ} \mathrm{C}$. A sample volume of $50 \mathrm{~mL}$ was poured into a glass measuring column firmly attached to a holder. At the base of the holder, a filter plate with a pore size 16 to $40 \mu \mathrm{m}$ was attached through which air needed for foam generation could pass through. Airflow was generated by the system at a rate of $0.2 \mathrm{~L} / \mathrm{min}$ for $20 \mathrm{~s}$. Foam height was measured using two arrays placed in parallel and surrounding the glass measuring column. One of the arrays emitted light whereas the other array detected the light that passed through the glass column. Each array was 
$1 \mathrm{~mm}$ away from the glass column to get the best resolution of foam height. A camera captured the foam structure generated by the air flow. A calibration was done with the dots printed at the top of the measuring column. The camera was then set at a height of $85 \mathrm{~cm}$ from the base in order to be closer to the foam-liquid interface. A medium field of view was set in order to have an optimum resolution for the bubble structure. Kruss Advance software analyzed all the data captured by the camera and the light sensor.

\section{Results and Discussion}

\subsection{Long-Term Thermal Stability}

The long-range heat stability was investigated in typical reservoir conditions on surfactant samples (10 $\mathrm{wt} \%$ in SW and DW) aged for a period sufficient to cause degradation. The surfactant samples were aged for 90 days at $90^{\circ} \mathrm{C}$, taken out and dried, and then subjected to NMR and FTIR analysis. The surfactants (OPAC, OPAS, and OPAH) revealed excellent stability under harsh conditions and NMR and FT-IR data showed no change in the original structure of surfactants. We display the NMR and FTIR analysis of the aged samples of OPAC here. The ${ }^{1} \mathrm{H}-\mathrm{NMR}$ data of the aged sample of OPAC (Figure 2, Table 1) revealed the survival of the surfactant tail by exhibiting the signals of $\mathrm{CH}_{3}$ and $\left(\mathrm{C}_{2}\right)_{n}$ moieties. The presence of $\mathrm{C}_{3}$ moieties connected to a quaternary ammonium headgroup [ $\left[\mathrm{R}-\underline{\mathrm{C}}_{3}-\mathrm{N}-\underline{\mathrm{C}}_{3}-\mathrm{R}\right]$ was also observed. The existence of $\mathrm{C}_{2}$ groups of EO units [- $\left.\underline{\mathrm{C}}_{2}-\underline{\mathrm{C}}_{2}-\mathrm{O}-\underline{\mathrm{C}}_{2}-\underline{\mathrm{C}}_{2}-\mathrm{O}-\right]$ was revealed by the overlapping peaks. The presence of an amide group [ $\mathrm{R}-\mathrm{C}=\mathrm{O}-\mathrm{N} \underline{\mathrm{H}}-]$ was confirmed by the broad peak of one proton. The 13C-NMR data of OPAC (Figure 3, Table 1) display signals of the $\mathrm{CH}_{3}$ and $\left(\mathrm{CH}_{2}\right)_{n}$ moieties of the surfactant tail. Methyl $\left[\mathrm{R}-\underline{\mathrm{C}} \mathrm{H}_{3}-\mathrm{N}-\underline{\mathrm{C}} \mathrm{H}_{3}-\mathrm{R}\right]$ and methylene $\left[-\underline{\mathrm{CH}_{2}}-\mathrm{CH}_{3}-\mathrm{N}_{-}-\mathrm{CH}_{3}-\underline{\mathrm{C}} \mathrm{H}_{2}-\right]$ carbons connected to a quaternary ammonium headgroup were also observed. The survival of the $\underline{\mathrm{C}} \mathrm{H}_{2}$ moieties of EO units was confirmed by the overlapping peaks. Carboxylate carbonyl $[\mathrm{R}-\mathrm{C}=\mathrm{O}-\mathrm{O}]$ and amide carbonyl $[\mathrm{R}-\underline{\mathrm{C}}=\mathrm{O}-\mathrm{NH}]$ were also observed. The FTIR data of OPAC (Figure 4) exhibited amide $[\mathrm{R}-\mathrm{C}=\mathrm{O}-\mathrm{NH}]$ stretching. The symmetric and asymmetric vibration of $\mathrm{C}-\mathrm{H}$ moieties of the hydrophobic tail was also observed. In addition, the stretching value of ether moieties $\left[-\mathrm{CH}_{2}-\mathrm{CH}_{2}-\mathrm{O}-\mathrm{CH}_{2}-\mathrm{CH}_{2}-\mathrm{O}-\right]$ was detected. Overall, the NMR and FTIR data of the aged sample of OPAC matched with the proposed structure.

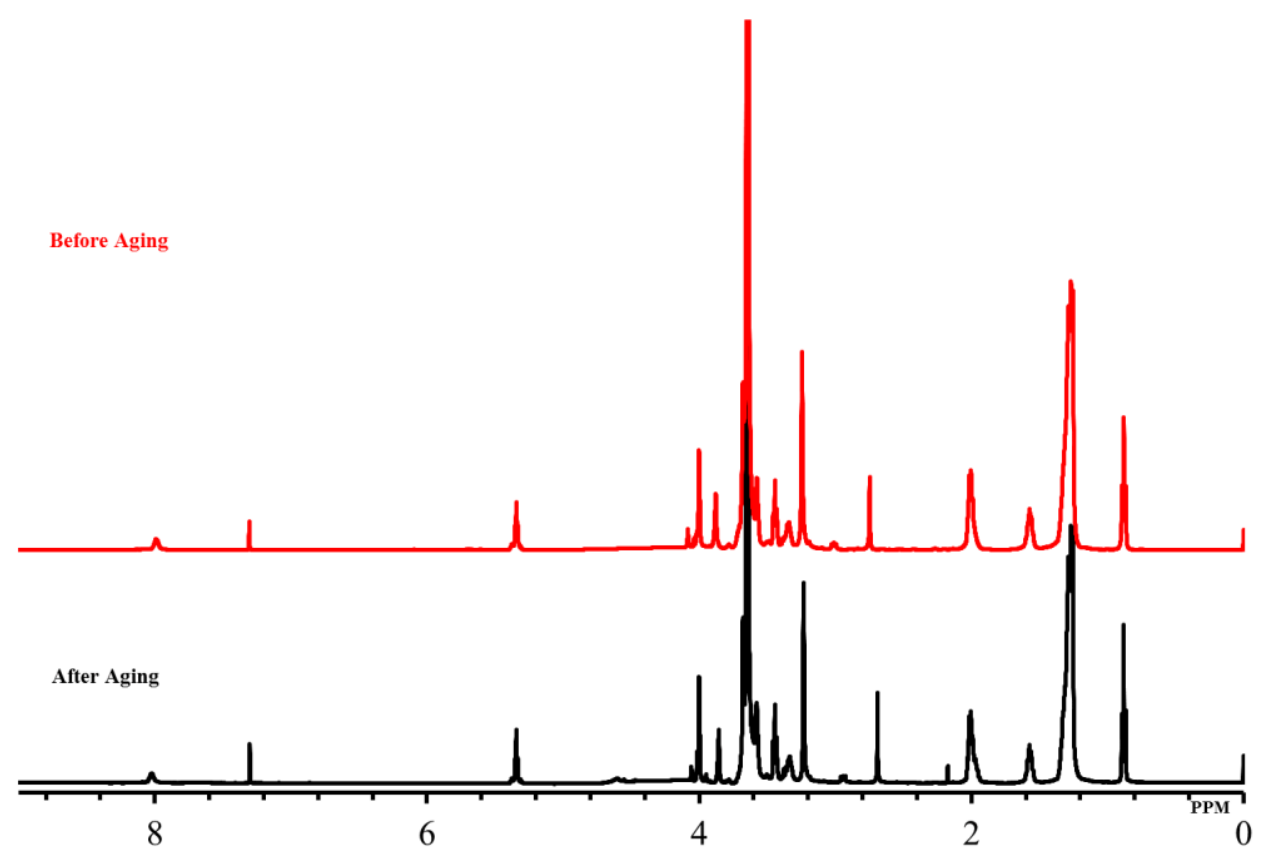

Figure 2. ${ }^{1} \mathrm{H}-\mathrm{NMR}$ spectra of oleyl polyoxyethylene amidopropyl carboxybetaine (OPAC) before and after aging. 
Table 1. NMR $(13 \mathrm{C}, 1 \mathrm{H})$ and FTIR data showing the description of different peaks for OPAC surfactant.

\begin{tabular}{|c|c|c|c|c|c|c|c|c|c|}
\hline \multirow{2}{*}{$\begin{array}{l}\text { Structural Assignment } \\
\text { of OPAC }\end{array}$} & \multicolumn{3}{|c|}{$\begin{array}{l}\text { Before Aging Chemical Shift } \\
\left(\text { ppm) FTIR }\left(\mathrm{cm}^{-1}\right)\right.\end{array}$} & \multicolumn{3}{|c|}{ After Aging in SW } & \multicolumn{3}{|c|}{$\begin{array}{l}\text { After Aging in Formation Water } \\
\text { (FW) }\end{array}$} \\
\hline & $1 \mathrm{H}$ & $13 C$ & FTIR & $1 \mathrm{H}$ & $13 \mathrm{C}$ & FTIR & $1 \mathbf{H}$ & $13 \mathrm{C}$ & FTIR \\
\hline $\begin{array}{l}\text { Terminal methyl }\left(\mathrm{CH}_{3}\right) \text { of } \\
\text { the hydrophobic tail }\end{array}$ & 0.88 & 13.9 & & 0.87 & 14.0 & & 0.88 & 14.1 & \\
\hline $\begin{array}{l}\text { Methylene }\left(\mathrm{CH}_{2}\right)_{n} \text { groups } \\
\text { of the hydrophobic tail }\end{array}$ & $1.18-1.38$ & $22.5-31.8$ & $\begin{array}{l}2855 \text { sym. } \\
2922 \text { asym. }\end{array}$ & $1.15-1.35$ & $22.5-31.7$ & $\begin{array}{l}2852 \text { sym. } \\
2920 \text { asym }\end{array}$ & $1.17-1.37$ & $22.6-31.8$ & $\begin{array}{l}2853 \text { sym. } \\
2921 \text { asym. }\end{array}$ \\
\hline $\begin{array}{l}\text { Unsaturated double bond } \\
\text { in the hydrophobic tail }\end{array}$ & 5.34 & $\begin{array}{c}129.7 \text { and } \\
129.8\end{array}$ & & 5.34 & $\begin{array}{c}129.7 \text { and } \\
129.8\end{array}$ & & 5.34 & $\begin{array}{c}129.8 \text { and } \\
129.9\end{array}$ & \\
\hline $\begin{array}{l}\text { Methyl }\left(\mathrm{CH}_{3}\right) \text { substitution } \\
\text { of quaternary ammonium }\end{array}$ & 3.23 & 51.1 & & 3.23 & 51.0 & & 3.24 & 51.2 & \\
\hline $\begin{array}{l}\text { Methylene }\left(\mathrm{CH}_{2}\right) \text { groups } \\
\text { of quaternary ammonium }\end{array}$ & $3.39-3.49$ & $\begin{array}{l}62.2 \text { and } \\
64.3\end{array}$ & & $3.40-3.50$ & $\begin{array}{l}62.2 \text { and } \\
64.3\end{array}$ & & $3.38-3.48$ & $\begin{array}{l}62.1 \text { and } \\
64.2\end{array}$ & \\
\hline $\mathrm{CH}_{2}$ groups of $\mathrm{EO}$ units & $3.54-3.74$ & $69.9-71.4$ & 1101 & $3.55-3.75$ & $69.8-71.5$ & 1105 & $3.56-3.76$ & $69.9-71.5$ & 1103 \\
\hline Amide group & 8.08 & 167.5 & 1656 & 8.07 & 167.4 & 1655 & 8.05 & 167.4 & 1657 \\
\hline
\end{tabular}

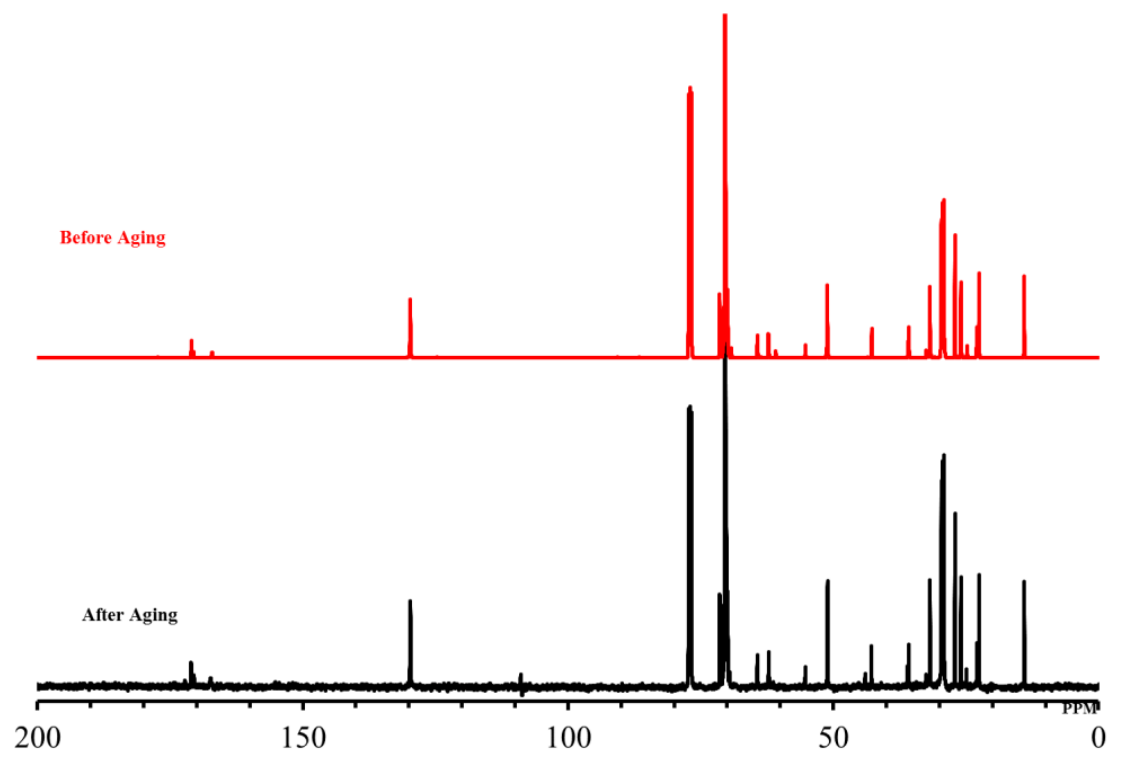

Figure $3 .{ }^{13} \mathrm{C}-\mathrm{NMR}$ spectra of OPAC before and after aging.

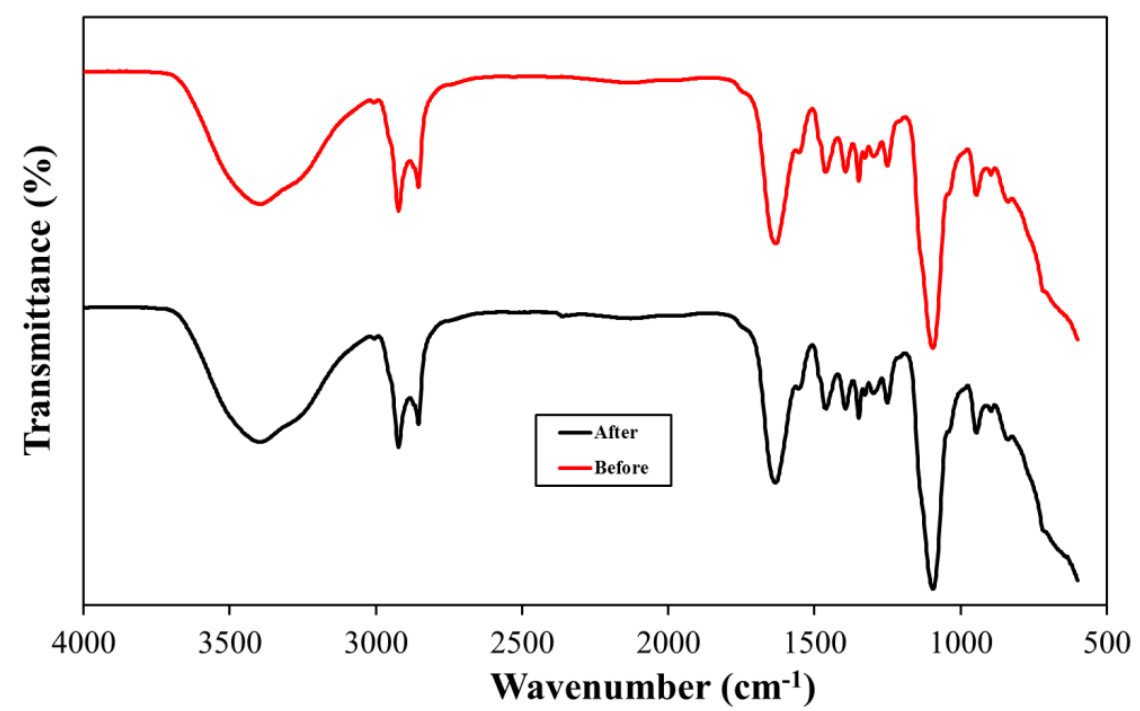

Figure 4. FTIR spectra of OPAC before and after aging. 


\subsection{Rheology}

The surfactant-polymer rheological parameters are complex and depend on the type of interaction between the surfactant and polymers. Figure 5 exhibits polymer viscosity at various OPAC concentrations. When AM-AMPS copolymer is dissolved in deionized water, the molecular chains repel each other and remain in an extended form. This increases the hydrodynamic volume and polymer viscosity. Adding any electrolyte could affect the polymer viscosity. When the surfactant is added, the cation of the surfactant neutralizes the intrinsic electrical charge on the polymer chain. This charge shielding results in the chain coiling, which decreases the interactions between the polymer chain. In addition, the hydration of the polymer chain also reduces, and the effective size of the swollen polymer decreases. As a result, the polymer viscosity is decreased by increasing the amount of surfactant. The shear rate is another factor that affects the viscosity of the polymer. At the low shear region, a Newtonian plateau was detected followed by the shear thinning region at a high shear rate for the solution of polymer in DW. The viscosity curve for surfactant-polymer solutions also showed a Newtonian plateau and shear thinning region. At low shear rates, the addition of surfactant has more impact on the polymer viscosity compared to the effect at high shear rates. In the Newtonian plateau, the addition of surfactant minimizes the polymer viscosity because of charge shielding and the shear has no effect on the viscosity. However, in the shear thinning region, viscosity reduction because of the surfactant concentration is not substantial. Similar flow curves were obtained when OPAH and OPAS surfactant were added to the AM-AMPS copolymer (Figures S1 and S2, Supplementary Materials). The addition of $0.1 \%$ OPAS, OPAH, and OPAC decreased the zero-shear viscosity of polymer by $54 \%$, $55 \%$, and $58 \%$, respectively. This shows that the change of the surfactant headgroup exhibited minor influence on the AM-AMPS copolymer viscosity.

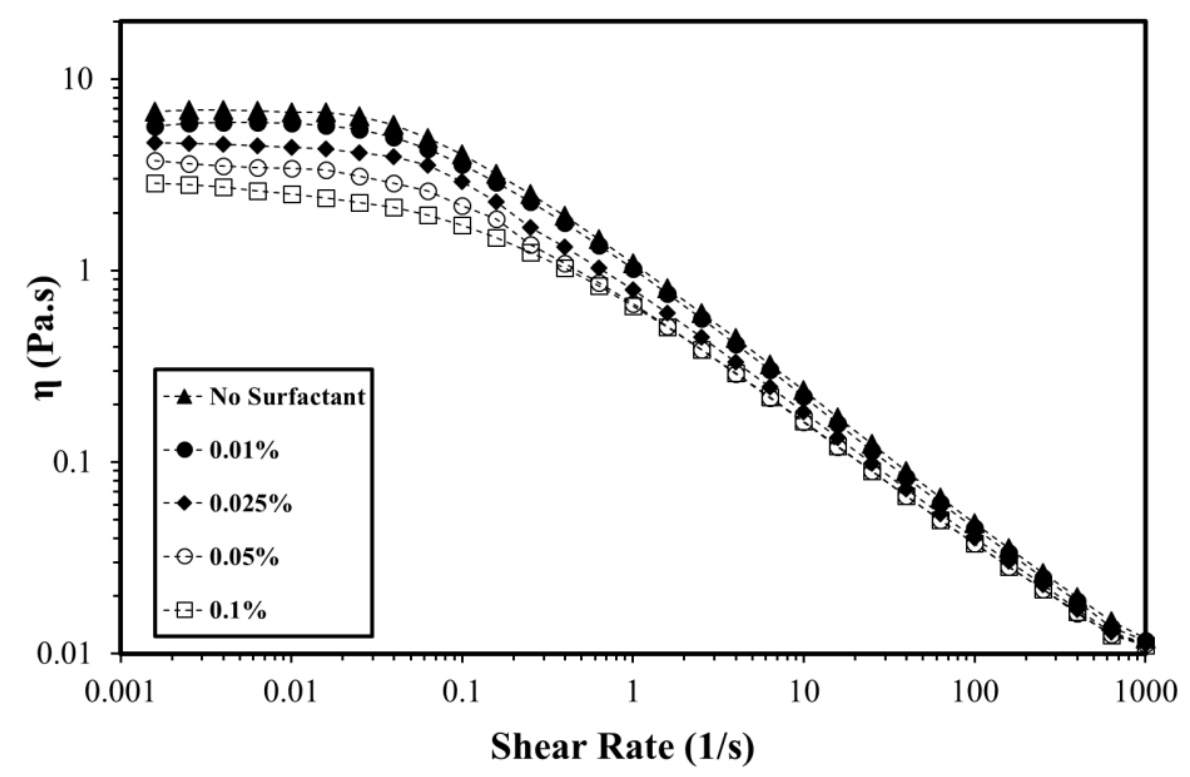

Figure 5. The viscosity of the polymer at different OPAC concentrations in deionized water $\left(\mathrm{T}=80^{\circ} \mathrm{C}\right.$, polymer concentration $=0.25 \%$ ).

The rheological behavior of the polymer in the presence of surfactant using deionized water was studied to isolate the effect of salts. In the absence of salts, the surfactant-polymer interaction was the only factor that determined the rheological response. However, the addition of salts in surfactant-polymer solutions could dramatically change various rheological parameters. Most oilfield applications are carried out using seawater, owing to the large amount needed. The rheological behavior of the polymer and surfactant-polymer (SP) solution was also evaluated when dissolved in synthetic seawater. Figure 6 shows the rheological behavior of the polymer and SP solutions when dissolved in seawater in the presence of OPAC surfactant. The seawater brings a huge amount 
of counterions that results in charge shielding and chain coiling as explained earlier. This charge shielding and chain coiling results in a reduction in the viscosity. However, in the seawater, the polymer viscosity was free from the concentration of surfactant. In deionized water, the only source of counterions that results in charge shielding and chain coiling comes from the surfactant. When polymers are dissolved in seawater, the counterions from the seawater coiled the chain and any added counterions from surfactant will have no effect on the reduction of viscosity and chain coiling. Hence, the viscosity is almost independent of the added surfactant. Similar results were reported for OPAH and OPAS surfactants (Figures S3 and S4, Supplementary Materials). The nature of the headgroup also become less important as far as the rheological properties of the SP solutions in high salinity brine are concerned. This suggests that for oilfield applications (high temperature, high salinity, and high shear), the concentration of the surfactant will not affect the rheological properties of the polymer. It is worth mentioning here that the surfactant concentration is decided after a rigorous screening by considering its interfacial properties, wettability alteration, and adsorption density on reservoir rock.

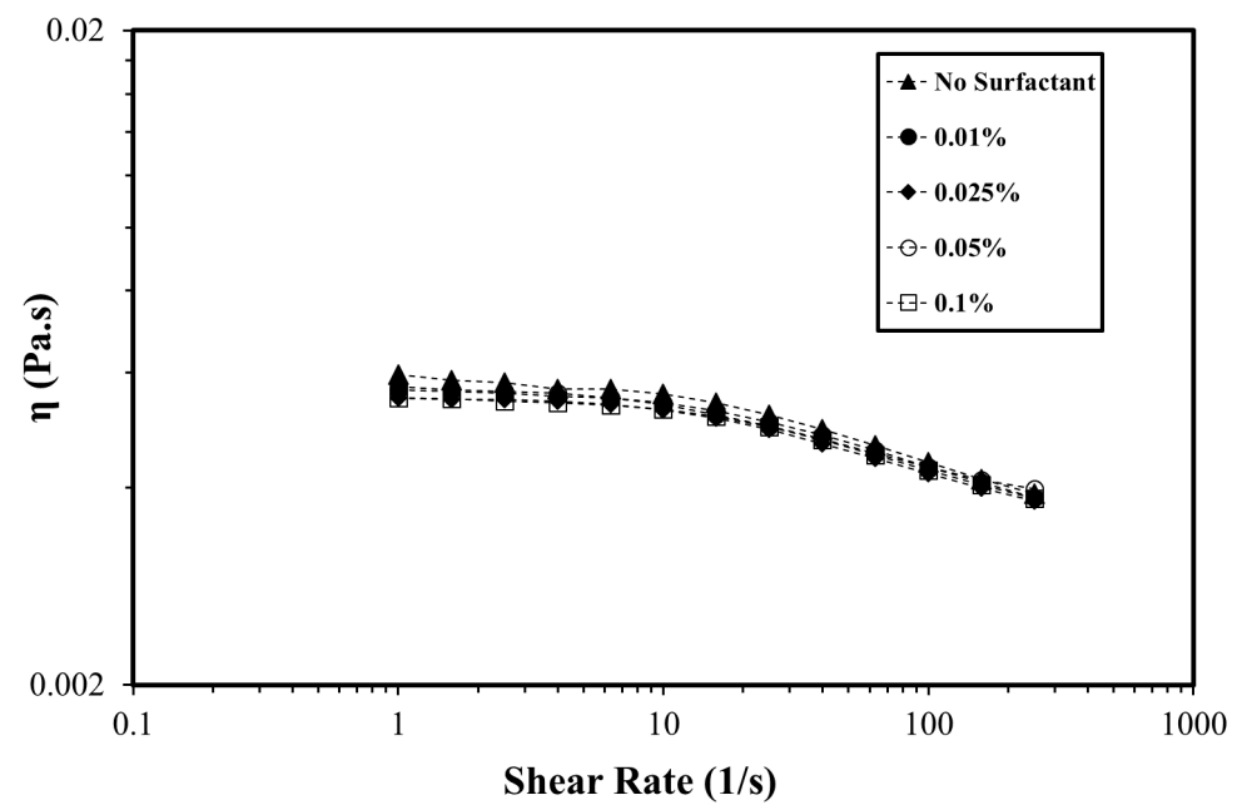

Figure 6. The viscosity of the polymer at different OPAC concentrations in seawater $\left(\mathrm{T}=80^{\circ} \mathrm{C}\right.$, polymer concentration $=0.25 \%$ ).

Dynamic shear rheology is also important for understanding the interactions between surfactant and polymers. In addition, it has been reported that the elasticity of the polymer helps in improving oil recovery [35-37]. Therefore, the storage modulus $\left(G^{\prime}\right)$ was determined at different surfactant concentrations and temperatures. Figure 7 shows the storage modulus of the polymer at different frequencies and concentrations of OPAC. The storage modulus was reduced by increasing the surfactant concentration. This is also associated with the charge shielding as explained earlier. The storage modulus of the polymer was reduced by $65 \%$ on addition of $0.1 \%$ OPAC surfactant. The reduction using the same concentration of OPAH and OPAS was 54\% and 50\%, respectively (Figures S5 and S6, Supplementary Materials). The effect of temperature on the viscosity of the polymer and SP solutions at varying OPAC concentrations is given in Figure 8. Polymer and SP solutions showed thermo-thinning behavior within the investigated temperature range. The viscosity of the polymer was reduced by increasing the concentration of the surfactant at all temperatures. A similar trend was observed using OPAH and OPAS surfactants (Figures S7 and S8). The minimum viscosity drop was observed with OPAS surfactant while the maximum viscosity drop was noted for OPAC. In summary, the rheological properties of the surfactant-polymer solutions strongly depend on the concentration of surfactant in the absence of salts. However, for practical field applications (high temperature, high salinity, and 
high shear rate), the effect of the surfactant concentration and type becomes less significant compared to the effect of salinity.

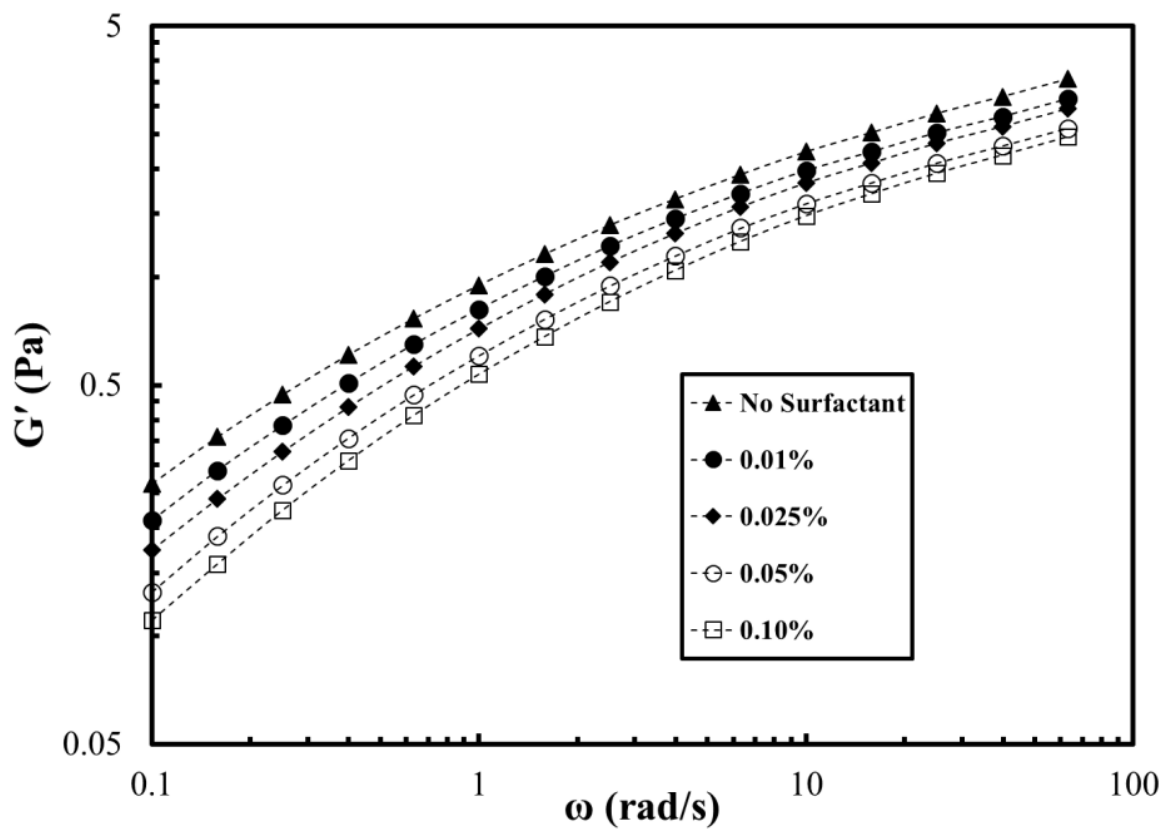

Figure 7. Storage modulus of the polymer at different OPAC concentrations in deionized water $\left(\mathrm{T}=80^{\circ} \mathrm{C}\right.$, polymer concentration $\left.=0.25 \%\right)$.

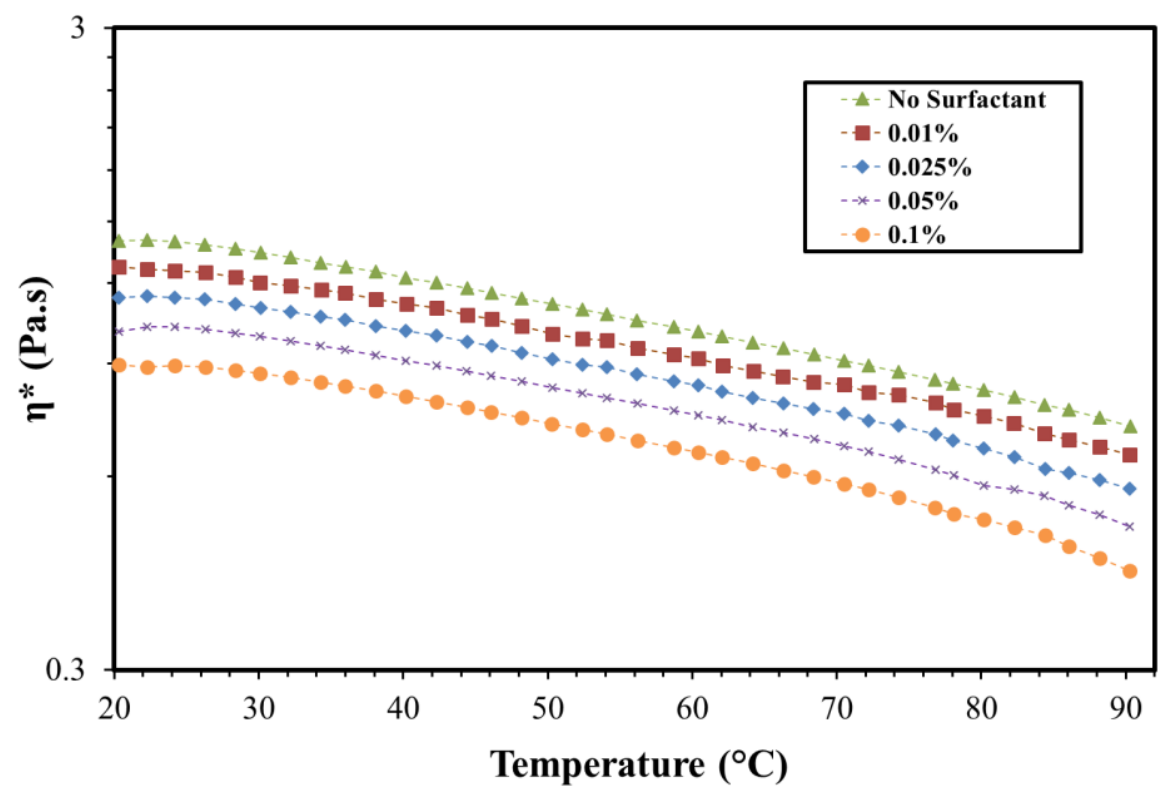

Figure 8. The viscosity of the polymer at different OPAC concentration in deionized water (frequency $=1 \mathrm{rad} / \mathrm{s}$, polymer concentration $=0.25 \%$ ).

\subsection{Foam Analysis}

The foam stability and foamability analysis were performed at a fixed concentration $(0.1 \%)$ of each surfactant in deionized water and synthetic seawater. The foamability of the surfactants was assessed by measuring the foam height when the air was injected for a fixed time $(20 \mathrm{~s})$ at $0.2 \mathrm{~mL} / \mathrm{min}$. The foamability data off all surfactants in deionized water and the synthetic seawater is given in Figures 9 and 10. The foamability of surfactants using deionized water was almost similar and there was no significant difference in the volume of foam generated regardless of the headgroup of the surfactants. 
The same observation was noted for surfactants in synthetic seawater. However, the foam generated using seawater was comparatively higher compared to the foam generated using deionized water. Salinity increases surfactant adsorption at the air-water interface and reduces electrostatic double layer repulsion between the surfactants. Increased adsorption enables more surfactant molecules to trap air, thus increasing foamability [38,39]. The balance between these two forces determines the initial foam height [40].

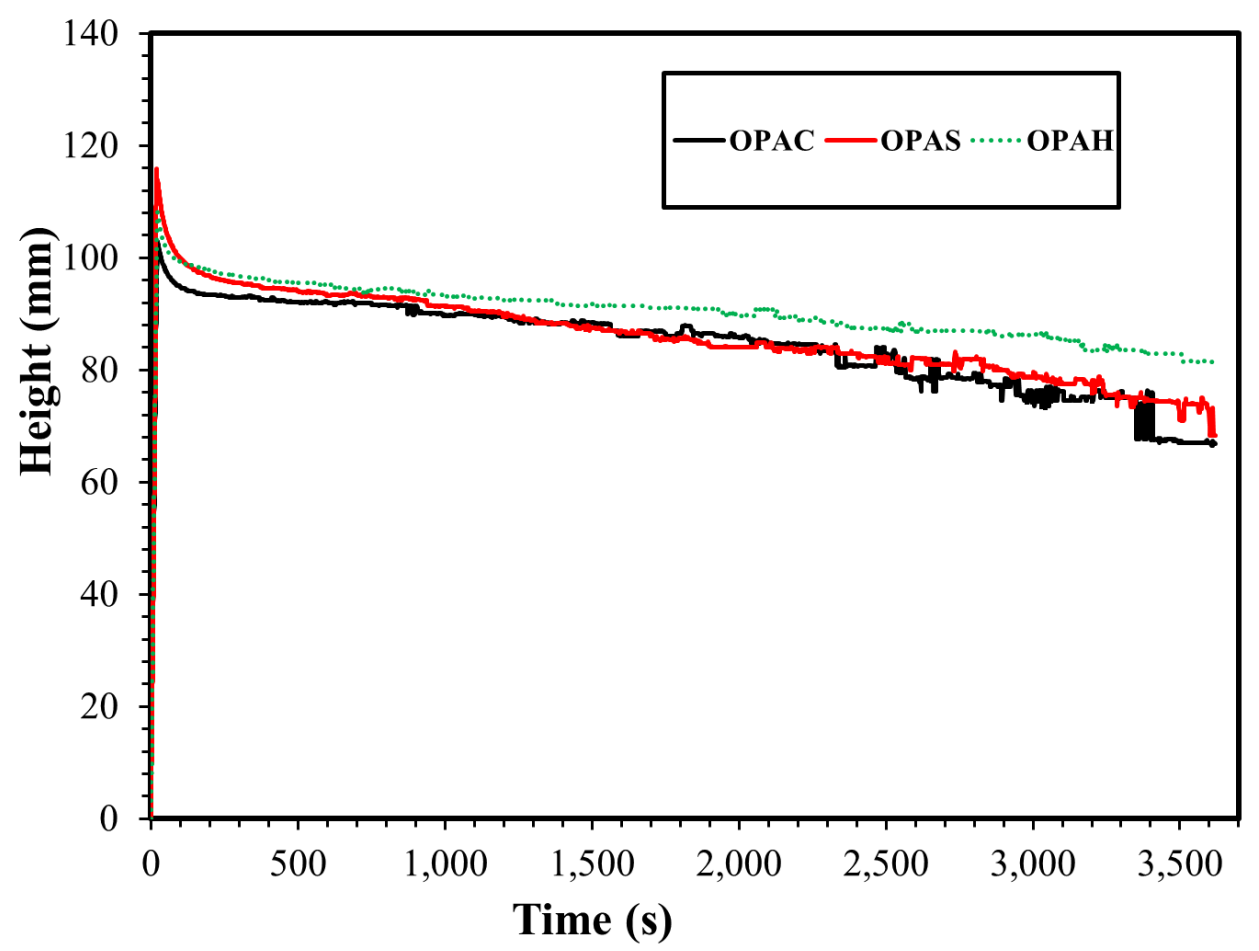

Figure 9. The foamability comparison of surfactants in deionized water.

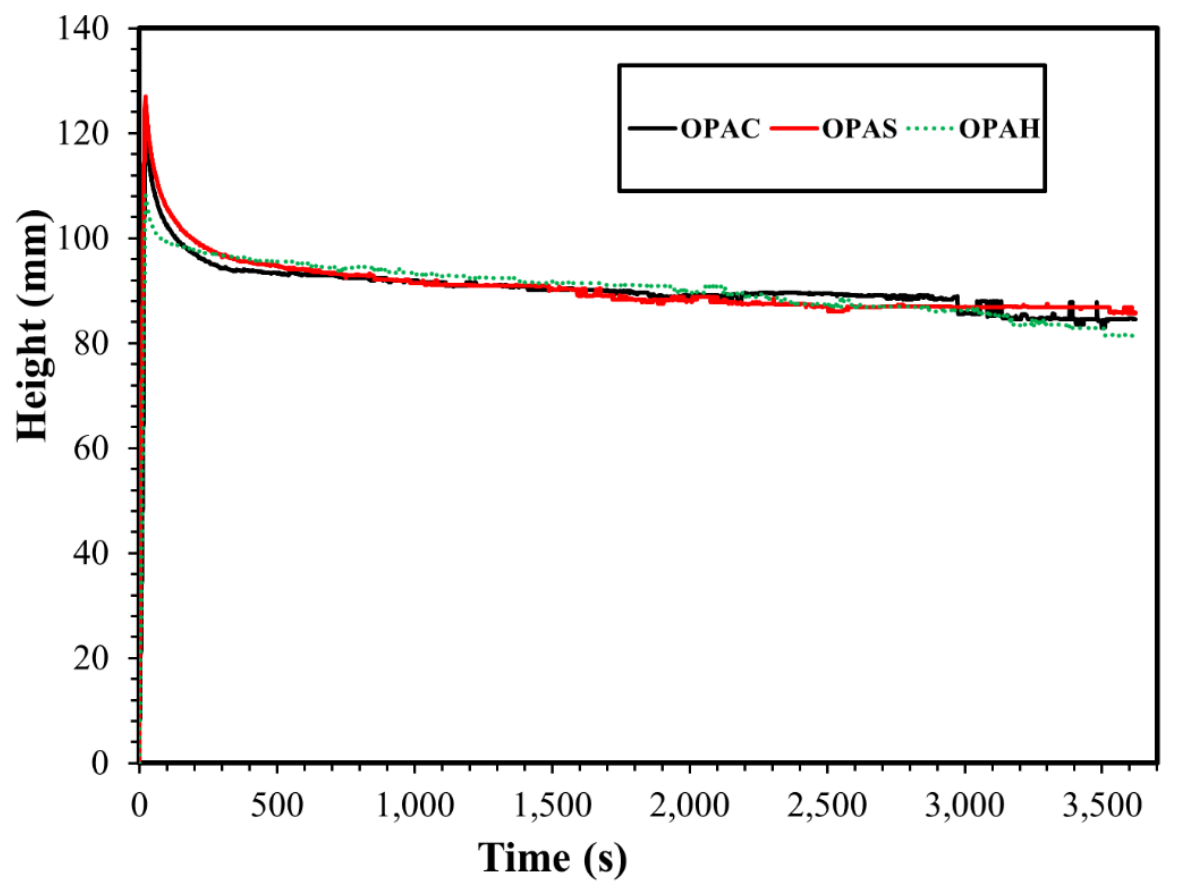

Figure 10. The foamability comparison of surfactants in synthetic seawater. 
Foam stability was assessed using the foam volume stability (FVS) parameter. The parameter FVS was calculated by the equations given below:

$$
\operatorname{FVS}(\mathrm{t})=\frac{\mathrm{V}_{\mathrm{t}(\text { foam })}}{\mathrm{V}_{\mathrm{f}(\text { foam })}} \times 100,
$$

where $\mathrm{V}$ is the volume, and subscript $\mathrm{t}$ refers to the volume at a given time, and $\mathrm{f}$ refers to the final condition (after foaming stopped or the end of the bubbling process).

Figure 11 shows the FVS of three surfactants in synthetic seawater as a function of time. After two hours, the FVS was $68 \%$ for surfactants OPAC and OPAS, while for OPAH it was $71 \%$. This negligible difference in foam stability suggests that for a given surfactant tail, FVS is independent of the headgroup. In addition, the FVS of each surfactant in synthetic seawater was higher compared to the corresponding FVS in deionized water (Figure S9). The structure of the foam at different times and conditions is given in Figure 12. It can be noted that the foam generated in the seawater solution is slightly denser compared to the foam generated in the deionized water for all surfactants. The foam structure also supports the foamability results as explained earlier. The foam structure pattern for all surfactants is almost similar and changing the headgroup does not make much of a difference on the foam structure.

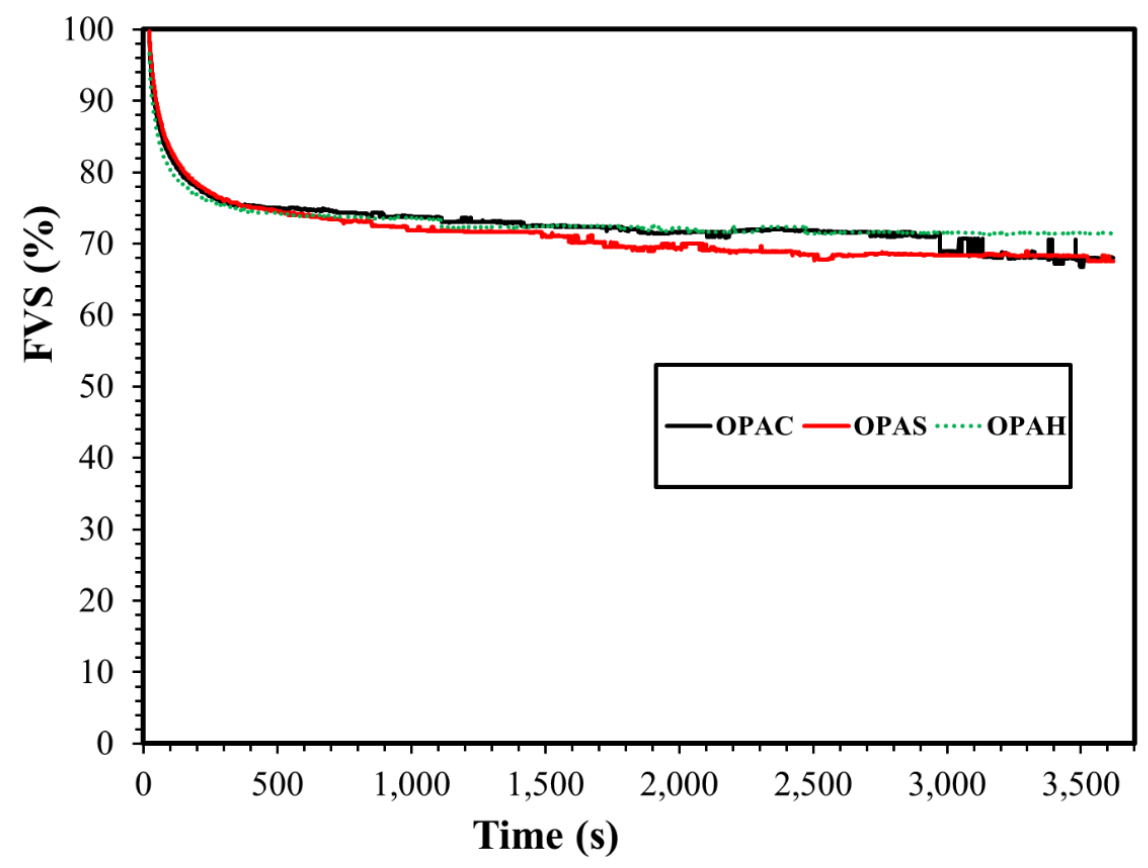

Figure 11. Foam volume stability of all surfactants in seawater. 


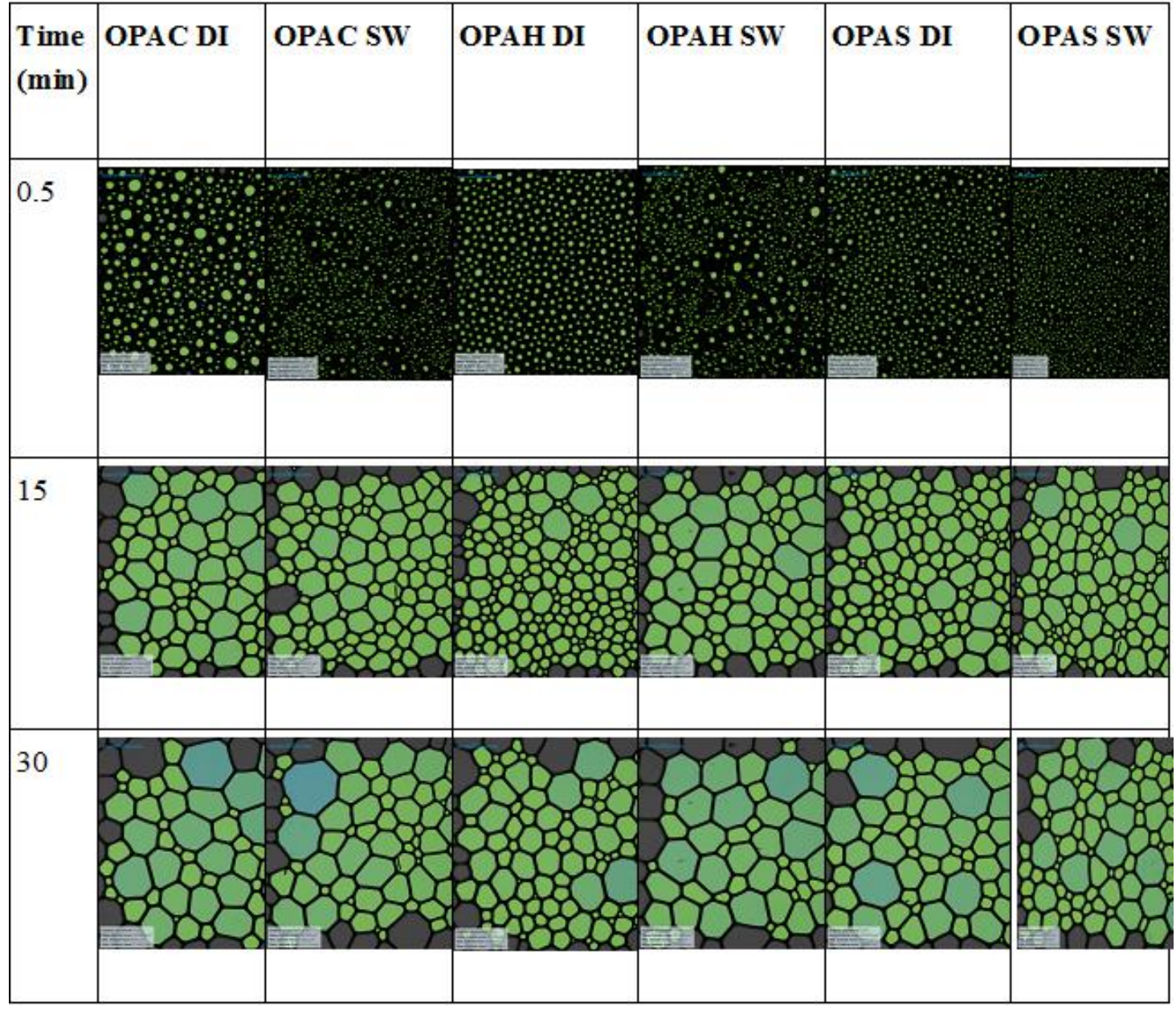

Figure 12. Structures of foam at different time intervals.

\section{Conclusions}

The selection of suitable surfactants for EOR application is a challenging task due to severe reservoir conditions, different types of rock, and poor thermal stability of commercially available surfactants. The synthesized betaine-based polyoxyethylene zwitterionic surfactants containing different headgroups (carboxybetaine, sulfobetaine, and hydroxysulfobetaine) showed excellent thermal stability as evidenced by ${ }^{1} \mathrm{H}-\mathrm{NMR},{ }^{13} \mathrm{C}$ NMR, and FTIR analysis. All peaks before and after 90 days of aging were similar and structural degradation was not observed. The thermal stability was independent of the nature of headgroup for all betaine-based polyoxyethylene zwitterionic surfactants. The rheological properties of surfactant-polymer solutions strongly depended on the interactions between the surfactant and polymers. Surfactant concentration and salt concentration affected the dynamic and steady shear rheological properties. However, at field conditions (high salinity, high temperature, and high shear), the effect of surfactant addition had a negligible effect on the viscosity and storage modulus of the polymer due to charge shielding by the added counterions. At high salinity conditions, the role of headgroup also became less significant for such a class of surfactants and similar rheological properties were obtained for polymer and surfactant-polymer solutions. The foamability and foam stability of the surfactants was high in the synthetic seawater compared to the deionized water. The maximum foam stability was achieved using OPAH, and OPAS showed minimum foam stability. However, the difference among the foam volume stability after two hours for the three surfactants was not significant. This works shows that thermal stability, surfactant-polymer rheological properties, and foamability of betaine-based polyoxyethylene zwitterionic surfactant are not affected by changing of the headgroup in typical reservoir conditions. Our current work focuses on optimizing 
the formulation to have the lowest interfacial tension and minimum retention that will be supported with coreflooding experiments in our future communication.

Supplementary Materials: The following are available online at http:/www.mdpi.com/2227-9717/7/12/908/s1.

Author Contributions: conceptualization, M.S.K. and S.M.S.H.; methodology, S.M.S.H.; data curation, M.S.K. and L.F.; writing — original draft preparation, S.M.S.H. and M.S.K.; supervision, M.S.K.; project administration, S.M.S.H.

Funding: This research was funded by College of Petroleum Engineering \& Geoscience (CPG), King Fahd University of Petroleum \& Minerals, through a joint project with UT Austin under the grant number CPG-17-0124 and the APC was funded by College of Petroleum Engineering \& Geoscience.

Acknowledgments: We are thankful to College of Petroleum Engineering \& Geoscience, King Fahd University of Petroleum \& Minerals, Saudi Arabia for providing financial support through collaborative work with UT-Austin to conduct this research.

Conflicts of Interest: The authors declare no conflict of interest.

\section{References}

1. Kamal, M.S.; Hussein, I.A.; Sultan, A.S. Review on Surfactant Flooding: Phase Behavior, Retention, IFT, and Field Applications. Energy Fuels 2017, 31, 7701-7720. [CrossRef]

2. Cheng, Y.; Yang, Y.; Niu, C.; Feng, Z.; Zhao, W.; Lu, S. Progress in synthesis and application of zwitterionic Gemini surfactants. Front. Mater. Sci. 2019, 248, 1-16. [CrossRef]

3. Nong, L.; Xiao, C.; Zhong, Z. Physicochemical properties of novel phosphobetaine zwitterionic surfactants and mixed systems with an anionic surfactant. J. Surfactants Deterg. 2011, 14, 433-438. [CrossRef]

4. Gerola, A.P.; Costa, P.F.; Nome, F.; Quina, F. Micellization and adsorption of zwitterionic surfactants at the air/water interface. Curr. Opin. Colloid Interface Sci. 2017, 32, 48-56. [CrossRef]

5. Zhang, Q.Q.; Cai, B.X.; Xu, W.J.; Gang, H.Z.; Liu, J.F.; Yang, S.Z.; Mu, B.Z. Novel zwitterionic surfactant derived from castor oil and its performance evaluation for oil recovery. Coll. Surf. A Phys. Eng. Asp. 2015, 483, 87-95. [CrossRef]

6. Zhou, M.; Zhang, Z.; Xu, D.; Hou, L.; Zhao, W.; Nie, X.; Zhou, L.; Zhao, J. Synthesis of three gemini betaine surfactants and their surface active properties. J. Taiwan Inst. Chem. Eng. 2017, 74, 7-13. [CrossRef]

7. Saxena, N.; Pal, N.; Dey, S.; Mandal, A. Characterizations of surfactant synthesized from palm oil and its application in enhanced oil recovery. J. Taiwan Inst. Chem. Eng. 2017, 81, 343-355. [CrossRef]

8. Pal, N.; Kumar, S.; Bera, A.; Mandal, A. Phase behaviour and characterization of microemulsion stabilized by a novel synthesized surfactant: Implications for enhanced oil recovery. Fuel 2019, 235, 995-1009. [CrossRef]

9. Pal, N.; Kumar, N.; Verma, A.; Ojha, K.; Mandal, A. Performance Evaluation of Novel Sunflower Oil-based Gemini Surfactant (s) with different Spacer Lengths: Application in Enhanced Oil Recovery. Energy Fuels 2018, 32, 11344-11361. [CrossRef]

10. Pal, N.; Saxena, N.; Laxmi, K.D.; Mandal, A. Interfacial behaviour, wettability alteration and emulsification characteristics of a novel surfactant: Implications for enhanced oil recovery. Chem. Eng. Sci. 2018, 187, 200-212. [CrossRef]

11. Olayiwola, S.O.; Dejam, M. A comprehensive review on interaction of nanoparticles with low salinity water and surfactant for enhanced oil recovery in sandstone and carbonate reservoirs. Fuel 2019, 241, 1045-1057. [CrossRef]

12. Mashayekhizadeh, V.; Kord, S.; Dejam, M. EOR potential within Iran. Spec. Top. Rev. Porous Med. Int. J. 2014, 5, 325-354. [CrossRef]

13. Saboorian-Jooybari, H.; Dejam, M.; Chen, Z. Heavy oil polymer flooding from laboratory core floods to pilot tests and field applications: Half-century studies. J. Pet. Sci. Eng. 2016, 142, 85-100. [CrossRef]

14. Gupta, R.; Mohanty, K.K. Temperature effects on surfactant-aided imbibition into fractured carbonates. In Proceedings of the SPE Annual Technical Conference and Exhibition, Denver, CO, USA, 21-24 September 2008.

15. Rostami, A.; Kamari, A.; Panacharoensawad, E.; Hashemi, A. New empirical correlations for determination of Minimum Miscibility Pressure (MMP) during N2-contaminated lean gas flooding. J. Taiwan Inst. Chem. Eng. 2018, 91, 369-382. [CrossRef]

16. Jia, B. Carbonated water injection (CWI) for improved oil recovery and carbon storage in high-salinity carbonate reservoir. J. Taiwan Inst. Chem. Eng. 2019, 104, 82-93. [CrossRef] 
17. Maurya, N.K.; Kushwaha, P.; Mandal, A. Studies on interfacial and rheological properties of water soluble polymer grafted nanoparticle for application in enhanced oil recovery. J. Taiwan Inst. Chem. Eng. 2017, 70, 319-330. [CrossRef]

18. Azad, M.S.; Trivedi, J.J. Novel viscoelastic model for predicting the synthetic polymer's viscoelastic behavior in porous media using direct extensional rheological measurements. Fuel 2019, 235, 218-226. [CrossRef]

19. Azad, M.S.; Dalsania, Y.K.; Trivedi, J.J. Capillary breakup extensional rheometry of associative and hydrolyzed polyacrylamide polymers for oil recovery applications. J. Appl. Polym. Sci. 2018, 135, 46253. [CrossRef]

20. Al-Anssari, S.; Arif, M.; Wang, S.; Barifcani, A.; Lebedev, M.; Iglauer, S. Wettability of nanofluid-modified oil-wet calcite at reservoir conditions. Fuel 2018, 211, 405-414. [CrossRef]

21. Ahmadi, M.A.; Galedarzadeh, M.; Shadizadeh, S.R. Wettability Alteration in Carbonate Rocks by Implementing New Derived Natural Surfactant: Enhanced Oil Recovery Applications. Trans. Porous Med. 2015, 106, 645-667. [CrossRef]

22. Ahmadi, M.A.; Shadizadeh, S. Experimental and Theoretical Study of a New Plant Derived Surfactant Adsorption on Quartz Surface: Kinetic and Isotherm Methods. J. Dispers. Sci. Technol. 2015, 36, 441-452. [CrossRef]

23. Ahmadi, M.A.; Zendehboudi, S.; Sha, A.; James, L. Nonionic Surfactant for Enhanced Oil Recovery from Carbonates : Adsorption Kinetics and Equilibrium. Ind. Eng. Chem. Res. 2012, 51, 9894-9905. [CrossRef]

24. Ahmadi, M.A.; Shadizadeh, S.R. Experimental investigation of adsorption of a new nonionic surfactant on carbonate minerals. Fuel 2013, 104, 462-467. [CrossRef]

25. Ahmadi, M.A.; Arabsahebi, Y.; Shadizadeh, S.R.; Behbahani, S.S. Preliminary evaluation of mulberry leaf-derived surfactant on interfacial tension in an oil-aqueous system: EOR application. Fuel 2014, 117, 749-755. [CrossRef]

26. Puerto, M.; Hirasaki, G.J.; Miller, C.A.; Barnes, J.R. Surfactant systems for EOR in high-temperature, high-salinity environments. SPE J. 2012, 17, 11-19. [CrossRef]

27. Li, P.; Yang, C.; Cui, Z.; Song, B.; Jiang, J.; Wang, Z. A new type of sulfobetaine surfactant with double alkyl polyoxyethylene ether chains for enhanced oil recovery. J. Surfactants Deterg. 2016, 19, 967-977. [CrossRef]

28. Kamal, M.S.; Shakil Hussain, S.M.; Fogang, L.T. A Zwitterionic Surfactant Bearing Unsaturated Tail for Enhanced Oil Recovery in High-Temperature High-Salinity Reservoirs. J. Surfactants Deterg. 2018, 21, 165-174. [CrossRef]

29. Sabhapondit, A.; Borthakur, A.; Haque, I. Characterization of acrylamide polymers for enhanced oil recovery. J. Appl. Polym. Sci. 2003, 87, 1869-1878. [CrossRef]

30. Kamal, M.S.; Hussien, I.A.; Sultan, A.S.; Han, M. Rheological study on ATBS-AM copolymer-surfactant system in high-temperature and high-salinity environment. J. Chem. 2013, 2013, 9. [CrossRef]

31. Boeije, C.S.; Bennetzen, M.V.; Rossen, W.R. A Methodology for Screening Surfactants for Foam Enhanced Oil Recovery in an Oil-Wet Reservoir. SPE Reserv. Eval. Eng. 2017, 20, 795-808. [CrossRef]

32. Wang, C.; Fang, H.; Gong, Q.; Xu, Z.; Liu, Z.; Zhang, L.; Zhang, L.; Zhao, S. Roles of catanionic surfactant mixtures on the stability of foams in the presence of oil. Energy Fuels 2016, 30, 6355-6364. [CrossRef]

33. Hussain, S.S.; Kamal, M.S.; Fogang, L.T. Synthesis and physicochemical investigation of betaine type polyoxyethylene zwitterionic surfactants containing different ionic headgroups. J. Mol. Struct. 2019, 1178, 83-88. [CrossRef]

34. Malik, I.A.; Al-Mubaiyedh, U.A.; Sultan, A.S.; Kamal, M.S.; Hussein, I.A. Rheological and thermal properties of novel surfactant-polymer systems for EOR applications. Can. J. Chem. Eng. 2016, 94, 1693-1699. [CrossRef]

35. Xia, H.; Wang, D.; Wu, J.; Kong, F. Elasticity of HPAM solutions increases displacement efficiency under mixed wettability conditions. In Proceedings of the SPE Asia Pacific Oil and Gas Conference and Exhibition, Brisbane, Australia, 18-20 October 2004.

36. Wang, D.; Cheng, J.; Xia, H.; Li, Q.; Shi, J. Viscous-elastic fluids can mobilize oil remaining after water-flood by force parallel to the oil-water interface. In Proceedings of the SPE Asia Pacific Improved Oil Recovery Conference, Kuala Lumpur, Malaysia, 6-9 October 2001.

37. Xia, H.; Ju, Y.; Kong, F.; Wu, J. Effect of elastic behavior of HPAM solutions on displacement efficiency under mixed wettability conditions. In Proceedings of the SPE Annual Technical Conference and Exhibition, Houston, TX, USA, 26-29 September 2004.

38. Behera, M.R.; Varade, S.R.; Ghosh, P.; Paul, P.; Negi, A.S. Foaming in micellar solutions: Effects of surfactant, salt, and oil concentrations. Ind. Eng. Chem. Res. 2014, 53, 18497-18507. [CrossRef] 
39. Varade, S.R.; Ghosh, P. Foaming in aqueous solutions of zwitterionic surfactant: Effects of oil and salts. J. Dispers. Sci. Technol. 2017, 38, 1770-1784. [CrossRef]

40. Wang, J.; Nguyen, A.V.; Farrokhpay, S. A critical review of the growth, drainage and collapse of foams. Adv. Colloid Interface Sci. 2016, 228, 55-70. [CrossRef]

(C) 2019 by the authors. Licensee MDPI, Basel, Switzerland. This article is an open access article distributed under the terms and conditions of the Creative Commons Attribution (CC BY) license (http://creativecommons.org/licenses/by/4.0/). 